\title{
Drosophila MOF controls Checkpoint protein2 and regulates genomic stability during early embryogenesis
}

Sreerangam NCVL Pushpavalli ${ }^{1 \dagger}$, Arpita Sarkar ${ }^{1 \dagger}$, M Janaki Ramaiah ${ }^{1 \dagger}$, Debabani Roy Chowdhury ${ }^{2}$, Utpal Bhadra ${ }^{2}$ and Manika Pal-Bhadra ${ }^{1^{*}}$

\begin{abstract}
Background: In Drosophila embryos, checkpoints maintain genome stability by delaying cell cycle progression that allows time for damage repair or to complete DNA synthesis. Drosophila MOF, a member of MYST histone acetyl transferase is an essential component of male X hyperactivation process. Until recently its involvement in G2/M cell cycle arrest and defects in ionizing radiation induced DNA damage pathways was not well established.

Results: Drosophila MOF is highly expressed during early embryogenesis. In the present study we show that haplo-insufficiency of maternal MOF leads to spontaneous mitotic defects like mitotic asynchrony, mitotic catastrophe and chromatid bridges in the syncytial embryos. Such abnormal nuclei are eliminated and digested in the yolk tissues by nuclear fall out mechanism. MOF negatively regulates Drosophila checkpoint kinase 2 tumor suppressor homologue. In response to DNA damage the checkpoint gene Chk2 (Drosophila mnk) is activated in the mof mutants, there by causing centrosomal inactivation suggesting its role in response to genotoxic stress. A drastic decrease in the fall out nuclei in the syncytial embryos derived from $m o f^{l} /+; m n k^{p 6} /+$ females further confirms the role of DNA damage response gene Chk2 to ensure the removal of abnormal nuclei from the embryonic precursor pool and maintain genome stability. The fact that mof mutants undergo DNA damage has been further elucidated by the increased number of single and double stranded DNA breaks.

Conclusion: mof mutants exhibited genomic instability as evidenced by the occurance of frequent mitotic bridges in anaphase, asynchronous nuclear divisions, disruption of cytoskeleton, inactivation of centrosomes finally leading to DNA damage. Our findings are consistent to what has been reported earlier in mammals that; reduced levels of MOF resulted in increased genomic instability while total loss resulted in lethality. The study can be further extended using Drosophila as model system and carry out the interaction of MOF with the known components of the DNA damage pathway.
\end{abstract}

Keywords: Mof, Mitosis, Syncytial embryos, Drosophila melanogaster, Chk2, Anaphase bridges

\section{Background}

In eukaryotic organisms the individual identity of cells is determined by cell specific genes while a set of genes that are expressed in all cells functions as housekeeping genes. Eukaryotic DNA is highly packaged into chromatin structures, with core histone and non histone chromosomal proteins that regulate many cellular processes including

\footnotetext{
* Correspondence: manikapb@gmail.com

${ }^{\dagger}$ Equal contributors

${ }^{1}$ Centre for Chemical Biology, Indian Institute of Chemical Technology, Hyderabad 500607, India

Full list of author information is available at the end of the article
}

DNA replication and repair of damaged DNA. Regulation of cell cycle involves processes that are crucial to the survival of a cell, wherein detection and repair of genetic damage occurs to control unwanted cell division and maintain genomic stability. Disruption of checkpoint function plays an important role in carcinogenesis and embryonic lethality [1,2]. Chromatin regulatory activities along with histone modifications facilitate the contact of repair proteins at the damaged sites and promote recruitment of components of signaling cascade. Acetylation of lysine 16 on histone $\mathrm{H} 4 \mathrm{H}$ (HK16Ac) has the potential to create or

\section{Biomed Central}


obscure binding platforms for chromatin modifying enzymes and transcriptional activators. Furthermore H4K16 acetylation can directly impact on higher order chromatin structure, thus creating an open highly accessible chromatin conformation. The major enzyme that acetylates H4K16 is MOF (Males Absent on First) which is highly conserved in mammals and Drosophila.

Drosophila histone acetyl transferase MOF is responsible for the interplay between the regulators of transcription and chromatin modifiers thereby governing the gene expression at transcriptional level. It belongs to the family of MYST histone acetyl transferases (HATs) which consists of a conserved catalytic MYST domain [3,4]. The members of this family display diverse roles in various nuclear processes and some of them have also been implicated in carcinogenesis [5]. MOF is an integral member in the Drosophila melanogaster dosage compensation process that ensures that males and females, despite unequal number of $\mathrm{X}$ chromosomes, express the same amount of X-linked gene products [6]. MOF has strict substrate specificity to H4K16 when compared to other HATs $[7,8]$. Drosophila mof was identified in a screen for ethyl methane sulfonate-induced male-specific lethal mutations and was shown to directly acetylate Histone H4 at K16 [9]. Deletion of mof in the case of both Drosophila and mammals caused substantial decrease in H4K16 acetylation indicating that mof is the major HAT for H4K16 [10,11].

Acetylation of H4K16 by MOF causes reduction in the chromatin compaction in vitro and decondensation of chromatin under in vivo conditions [12,13]. Hence MOF regulates chromatin based activities such as transcription and DNA damage repair by H4K16 acetylation. Moreover MOF is an important constituent of X-chromosome dosage compensation complex (DCC) resulting in two fold activation of X-linked genes in male flies. Males carrying loss of function mof mutation do not survive since they lack the H4K16Ac enrichment on the X-chromosome for transcription of the X-linked genes [6,14]. Interestingly mammalian MOF has high degree of sequence similarity to Drosophila MOF protein and H4K16 acetylation is also an epigenetic signature of cellular proliferation during embryogenesis and oncogenesis [15]. Further the role of MOF in ionizing radiation (IR) response is also conserved in Drosophila [11]. Recent studies in mammals suggest that the levels of H4K16 acetylation were reduced both in cancer cell lines and primary tumors [16]. Increased genomic instability, with high spontaneous chromosomal aberrations and reduced $\gamma-\mathrm{H} 2 \mathrm{AX}$ foci formation after IR treatment are characteristic features of cultured $m M o f^{t^{+-}}$ cells. In the case of mammals total loss of function ( $m o f^{{ }^{\prime-}}$ ) resulted in lethality [15].

Faithful transmission of genetic information in cellular organisms is carried out by two basic processes such as DNA replication and cell division. The first 13 syncytial nuclear divisions in Drosophila are maternally controlled and consist mainly of $\mathrm{S}$ and $\mathrm{M}$ phases with short or undetectable gap phases [17]. The syncytial cycles from 17 occur inside the embryos and nuclear migration to the cortex occurs during cycles 8 and 9 where further synchronous divisions take place before the onset of cellularisation at $14^{\text {th }}$ nuclear cycle. During cycle 9 few nuclei migrate to the poles to form the pole cells that become the germ cells of the embryo [18]. After completion of 13 syncytial cycles, the embryo undergoes cellularization. Cell cycle checkpoints maintain genomic integrity and stability by regulating the progression of the cell cycle and inducing apoptosis in response to DNA damage to eliminate deleterious mutations from the genome. Defects in cell cycle checkpoints cause a wide variety of defects such as aging, genetic diseases, oncogenesis and neurodegeneration. Proper balance of cell cycle responses are critical for cell death or cell survival to occur. Though DNA damage and replication checkpoint induced apoptosis has been extensively studied, less is known about the cellular responses to stress during mitosis. Checkpoint failures lead to progression of mitosis without damage repair leading to mitotic catastrophe. Embryos exhibiting mitotic catastrophe have giant and fragmented nuclei lacking a regular pattern and $2 \mathrm{~N}$ ploidy [19].

In the present study we report the identification and phenotypic characterization of Drosophila mutants which are haplo-insufficient for maternal MOF. During early embryogenesis mutation in Drosophila mof leads to spontaneous chromosomal aberrations and genomic instability leading to mitotic cell cycle progression without repair of damaged DNA. Most significantly, we found the activation of Drosophila homolog of the checkpoint kinase 2 (DmChk2 or $m n k)$ in response to mof mutation causing centrosomal inactivation. We propose that Drosophila MOF, like its human counterpart, is required for maintaining genomic stability during embryogenesis.

\section{Results}

\section{mof heterozygote embryos are haplo-insufficient for} maternal MOF gene product

$m o f^{d}$ is a EMS mutation having a single amino acid substitution in the acetyl co-enzyme motif [9]. Sequence analyses revealed that $m o f^{3}$ results from a nonsense mutation at aminoacid 151 (Q151X) [11]. The nature of the mof alleles has been studied by quantifying the amount of maternal MOF gene product. For this purpose total protein was isolated from control $\left(y w^{67 c 23}\right)$ mof (Ethyl Methane Sulphonate mutation) and $m o f^{\beta}$ (non-sense mutation) embryos (1-2 h) and western blot analysis was carried out using MOF antibody. A drastic decrease in MOF expression in mof heterozygote embryos compared to wild type controls indicated that mof mutation is haplo-insufficient for maternal gene product (Figure 1). 

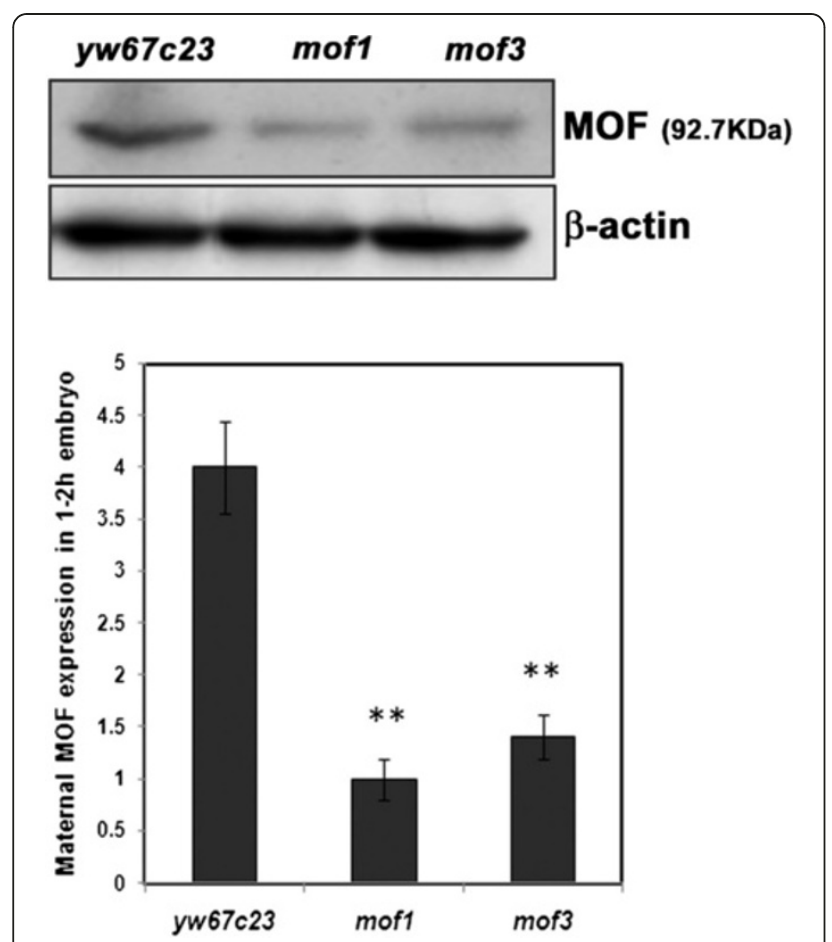

Figure 1 Haplo-insufficiency of mof $^{1}$ heterozygotes. Total protein was isolated from early embryos of control ( $\left.\mathrm{yw}^{67 \mathrm{c} 23}\right)$, mof ${ }^{1}$ and $\operatorname{mof}^{3}(1-2 h)$ and western blot analysis carried out using mof antibody has shown 3-fold reduction in the maternal MOF protein. $\beta$-actin is used as an internal loading control. Statistical significance was assessed using student t-test. ${ }^{* *}$ indicates $\mathrm{P}<0.001$, ** indicates $\mathrm{P}<0.01,{ }^{*}$ indicates $\mathrm{p}<0.05$.

\section{Asynchronous cell cycle and Mitotic catastrophe in the mof embryos}

MOF is a highly conserved MYST family HAT that acetylates histone at H4K16 and plays an important role in transcriptional activation. Studies of mof null mice showed delayed development with massive abnormal chromosomal aggregation, leading to death at an early stage [15]. In vitro and as well as in vivo studies in Drosophila has shown that MOF is required for efficient repair of DNA damage induced by ionizing radiation [11]. Since $m o f$ mutants are haplo-insufficient for the maternal gene product, we were interested to study the role of MOF during early mitotic divisions that are syncytial. Embryos derived from heterozygous mothers (haplo-insufficiency of maternal gene product) of $m o f^{1} / F M 7$ (EMS mutagenesis), $m o f^{3}$ / FM7 (non-sense mutation) as well as $y w^{67 c 23}$ (control) were collected. Early embryos ( $0-2$ h) were fixed and mounted in propidium iodide (PI) to visualise the nuclei. mof heterozygote embryos exhibited mitotic catastrophe with fragmented nuclei that appear as large mass of chromatin compared to wild type control where the nuclei appeared normal (Figure 2A). During early embryogenesis the initial seven syncytial divisions occur at the interior of the embryo. During cycles 8 and 9 the nuclei migrate to the cortex leaving only few yolk nuclei. We observed that abnormal nuclei in the mof heterozygote embryos are eliminated by nuclear fallout mechanism where in they are digested inside the yolk tissues. Nuclear fallout mechanism protects the organism by eliminating the abnormal nuclei from forming adult structures that might be deleterious. Nearly $70 \%$ of the mof heterozygotes exhibited a large number of fall out nuclei (high severity fall out nuclei=more than 5 fall out nuclei/embryo) (Figure 2B, $2 \mathrm{C})$ compared to control nuclei $\left(y w^{67 c 23}\right)$ where the number of fall out nuclei is negligible. Hence a decreased number of nuclei are present in the mof embryos compared to control $\left(y w^{67 c 23}\right)$. The fall out nuclei in embryos were scored when they are $2-20 \mu \mathrm{m}$ below the cortex in the syncytial blastoderm stage as they are mis-interpretated in later stages where fall out co-exists with normal nuclear migration.

\section{Abnormal mitosis in mof heterozygotes}

$M o f$ is a maternal effect gene and homozygotes for mof mutation do not survive (late larval lethal) till adult stage [11]. To study the role of MOF in early mitosis, we collected embryos derived from heterozygous mothers (haplo-insufficiency of maternal gene product) of $m o f^{1}$ / FM7 and $y w^{67 c 23}$ (control). During the early syncytial nuclear divisions, $m o f^{d}$ mutant embryos exhibited several mitotic defects such as chromatid bridges resulting in lagging chromosomes (Figure 3A), defects in sister chromatid separation (Figure 3B); telophase defects (Figure 3C) indicating that mof heterozygous embryos may be entering mitosis with damaged or incompletely replicated DNA. The lethality associated with mof homozygotes was fully rescued with the addition of mof transgene. Although the transgenic line expressing mof transgene was viable and fertile, it did not completely restore the chromosomal defects (only $60 \%$ of the defects were rescued) (Additional file 1). The embryos from $m o f^{d} /+$ display similar mitotic defects as that of $m o f / F M 7$ while the embryos from $F M 7 /+$ females do not show any mitotic defects indicating that FM7 balancer has no role in causing the mitotic defects observed in the case of mof /FM7 embryos (data not shown).

\section{Mitotic asynchrony during early nuclear divisions in mof heterozygous embryos}

In early embryos of wild type mitosis occurs synchronously and proceeds in the form of waves starting from the poles. Mitotic synchrony during pre-syncytial and syncytial divisons in $m o f^{d}$ and control embryos was studied by staining with antibody against Histone H3 Ser10 Phosphorylation (PH3) (the mitosis marker). Control embryos showed PH3 staining on all the chromsomes while in the case of $m o f^{d}$ heterozygotes both $\mathrm{PH} 3$ positive (dividing) and PH3 negative (non-dividing) chromosomes were observed. Thus the PH3 negative chromosomes in mof 


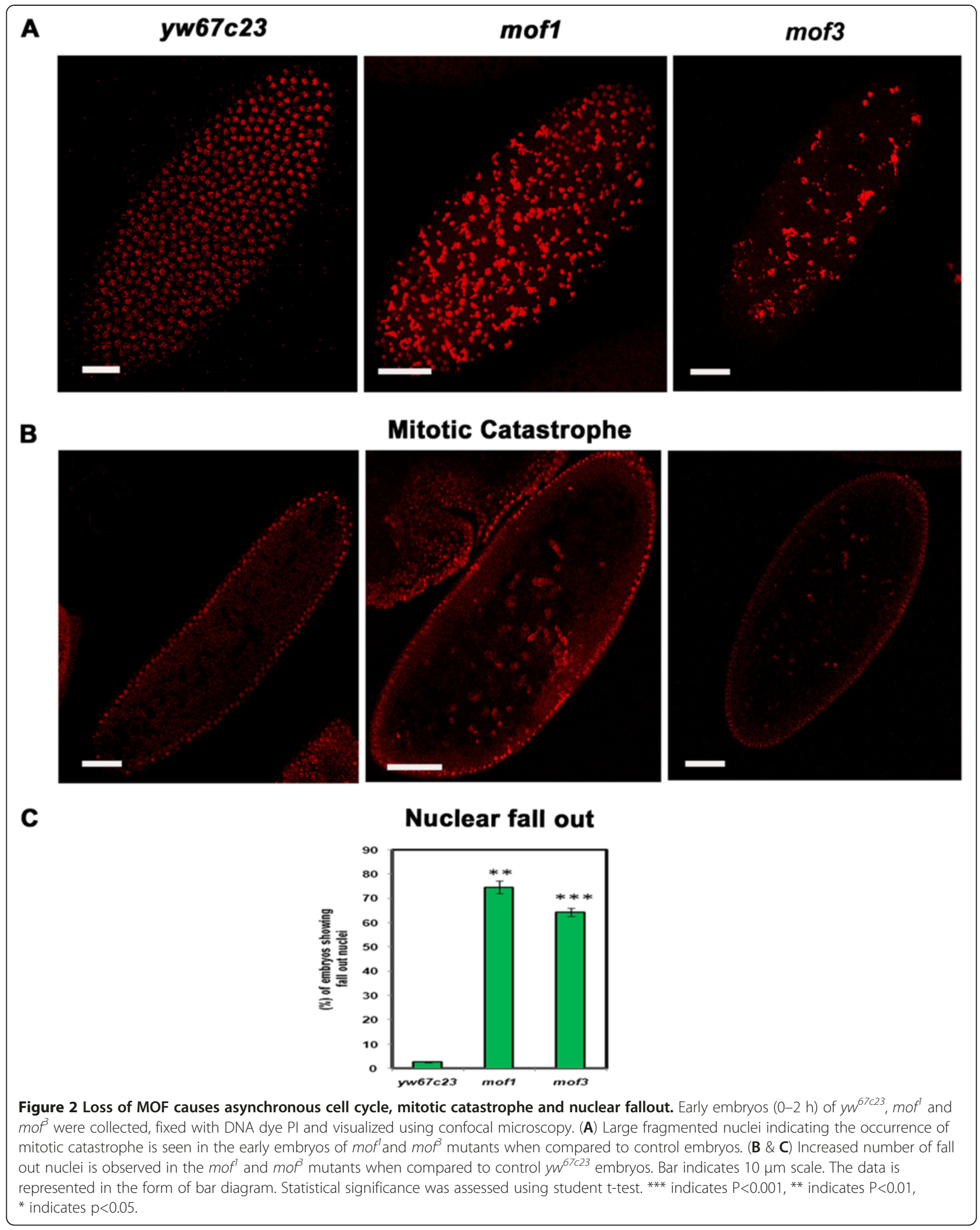




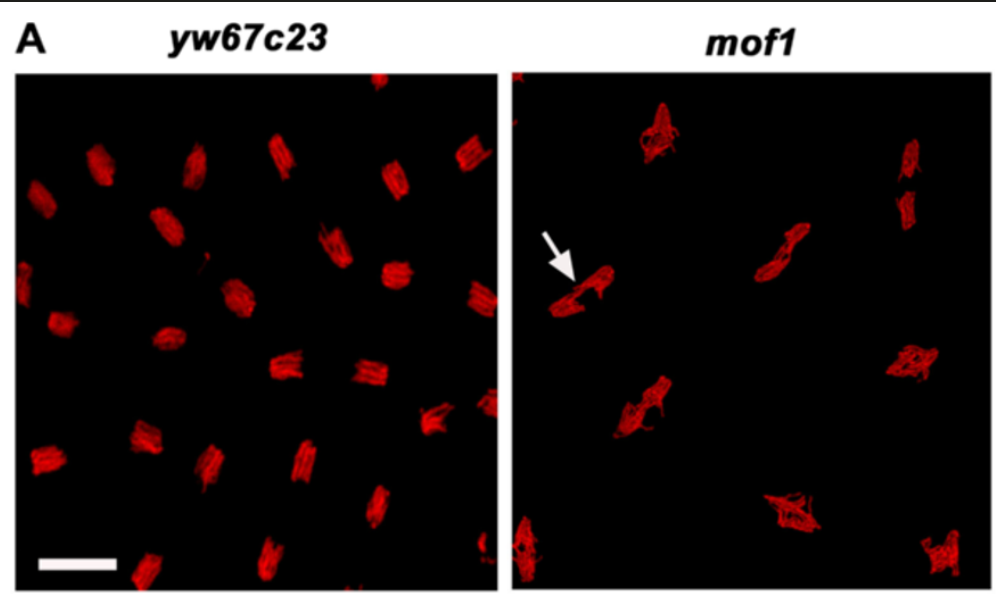

\section{B Chromatid bridges}

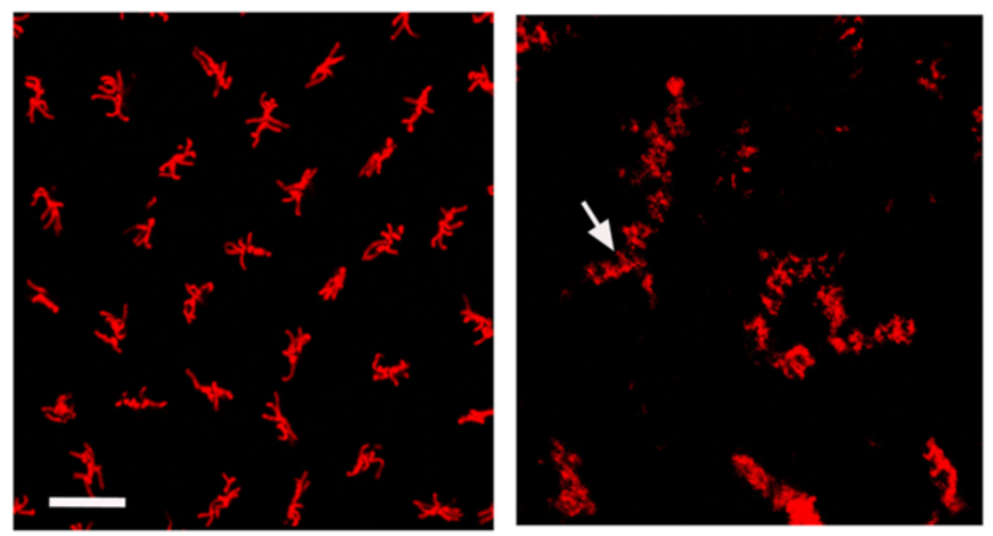

\section{Abnormal Mitotic Figures}

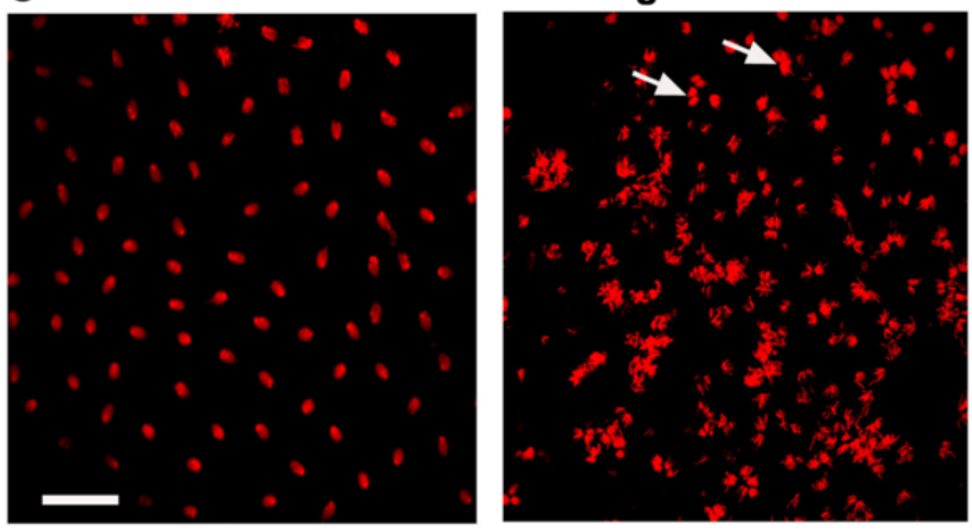

\section{Telophase defects}

Figure 3 Loss of maternal MOF causes chromsomal defects in early embryos. Early embryos (0-2 h) from mof and yw ${ }^{67 c 23}$ were collected, fixed with DNA dye PI and visualised using confocal microscopy. The mof mutants displayed a wide variety of chromosomal defects like (A) chromatid bridges which indicates the presence of lagging chromosomes (B) sister chromatid separation and (C) telophase defects. Bar indicates $10 \mu \mathrm{m}$ scale. 
heterozygotes indicate the existence of abnormal nuclei. Our data indicates that maternal supply of MOF is required for mitotic synchrony in pre-syncytial and syncytial blastoderm embryos (Figure 4A-A', B-B'). These abnormal nuclei which loose association with cortex (fall out nuclei) are unlikely to divide since they do not have centrosomes attached to them. To further confirm nuclear fallout early embryos of $m o f^{d}$ heterozygotes and $y w^{67 c 23}$ were immunostained with anti-centrosomin antibody. A number of free centrosomes lacking the chromosomes

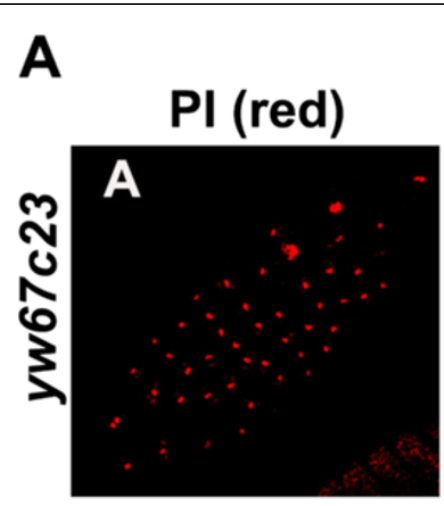

\section{Pre-syncytial}
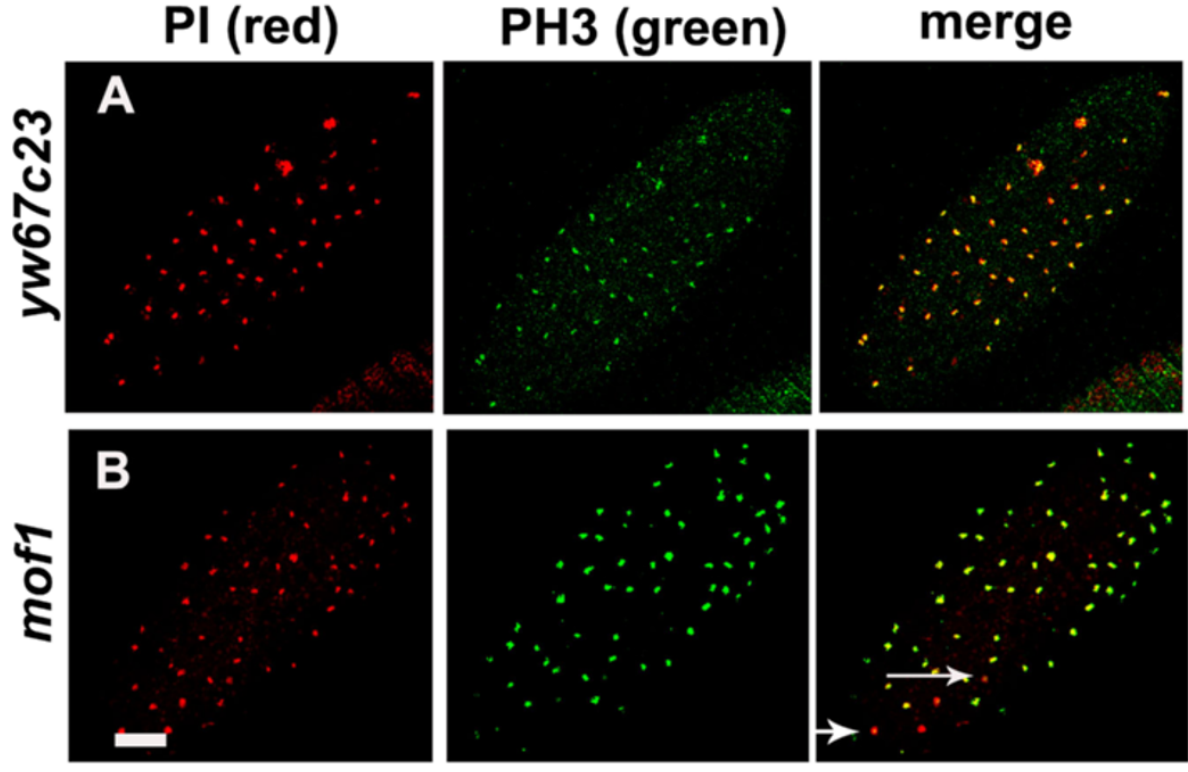

B
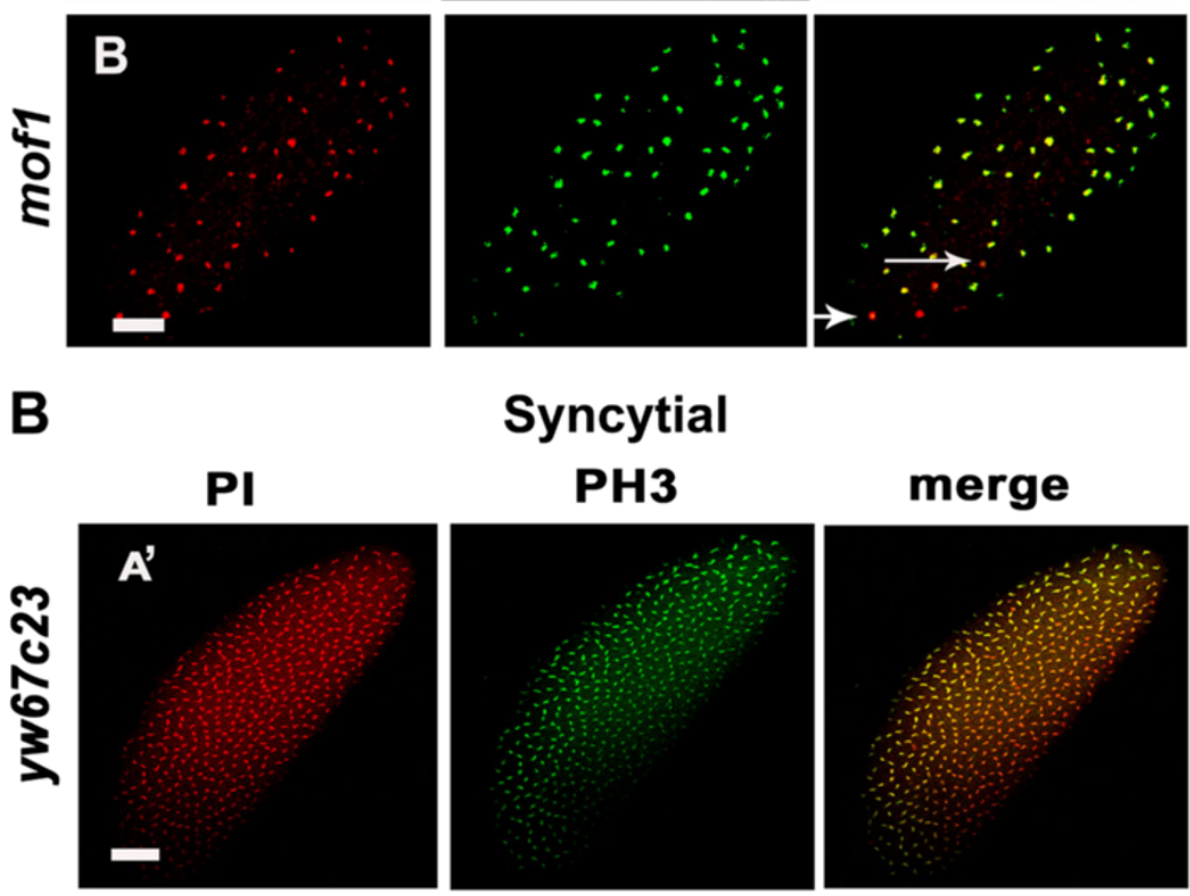

Syncytial PH3

\section{merge}
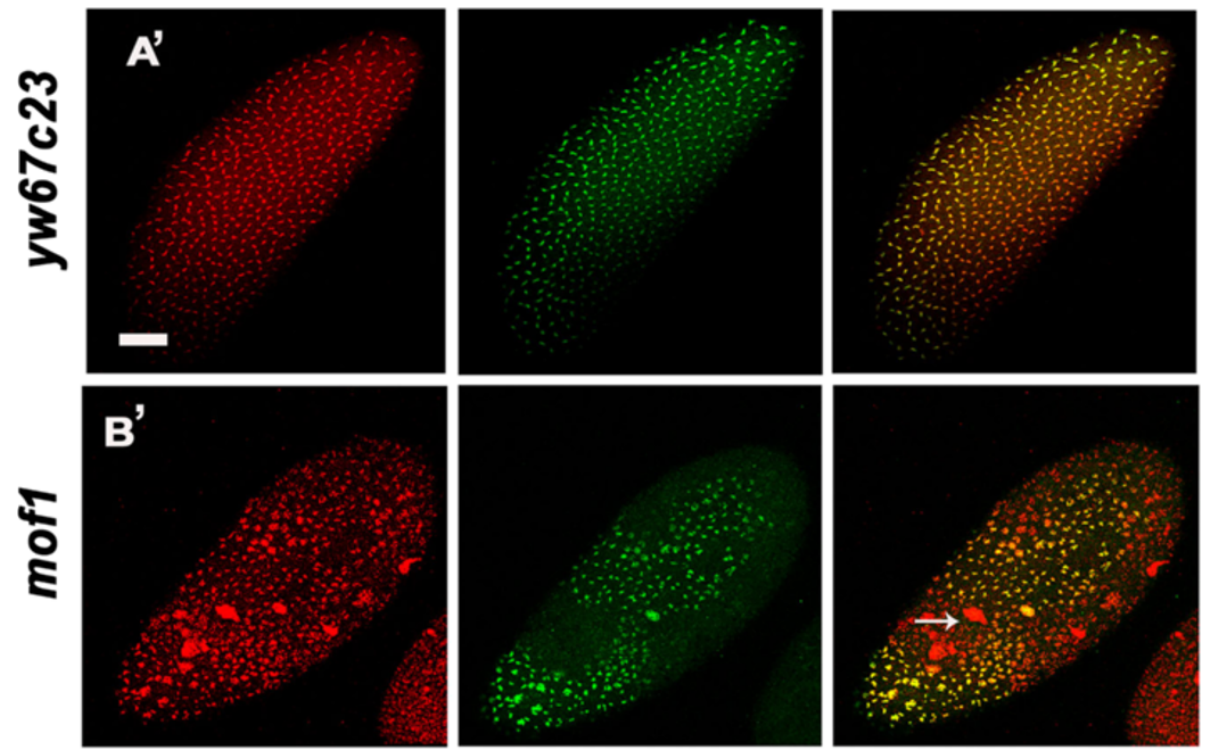

Figure 4 Mitotic asynchrony in mof $^{1}$ heterozygotes. Early embryos from $0-2 \mathrm{~h}$ were collected from control yw $w^{67 c 23}$ and mof mutants and immunostaining was carried out using PH3 antibody (green) which is mitotic marker. DNA was stained with PI (red). A and $\mathrm{A}^{\prime}$ represents control $y w^{67 c 23}$ while $\mathbf{B}$ and $B^{\prime}$ represents mof embryos during pre-syncytial and syncytial blastoderm stages respectively. In the case of mof $f^{\prime}$ embryos the nuclei are unevenly spaced and not all chromsomes are stained with PH3 indicating the existance of mitotic asynchrony during pre-syncytial blastoderm stage. Bar indicates $10 \mu \mathrm{m}$ scale. 
were present in the $m o f^{d}$ heterozygous early embryos compared to control embryos $\left(y w^{67 c 23}\right)$. The free centrosomes in the embryo indicated the presence of abnormal nuclei that are eliminated by the nuclear fallout mechanism (Figure 5). In addition to free centrosomes we also observed chromosomes lacking centrosomes or with only one centrosome. These findings strongly suggest the involvement of centrosome inactivation in the mof early embryos.

\section{Disruption of cytoskeleton in the mof heterozygous embryos}

Cytoplasmic organization, nuclear division and nuclear migration in the syncytial embryos are modulated by the cytoskeletal proteins. Following the syncytial divisions individual cells are produced by a process called cellularization that occurs during interphase of nuclear cycle 14 . Thus we were interested to study the changes in the organization of actin cytoskeleton and hence control $y w^{67 c 23}$ and $m o f^{1}$ heterozygous embryos were immunostained with $ß$-actin antibody. The typical honeycomb like structure of actin cytoskeleton observed in the control was lacking in the case of $m o f^{l}$ embryos. Moreover in the mof embryos chromosomes were incompletely surrounded by the actin filaments along with few small cells that lack nuclei. These empty cells indicate the presence of abnormal nuclei which have been eliminated by nuclear fall out mechanism (Figure 6). In addition to the actin filaments the polymerization and depolymerization of microtubule network helps in mediating the coordinated nuclear movement (chromosomes) during syncytial stage of embryogenesis. Since polymerization and depolymerization of the microtubules is required for proper chromosome movement, we stained the $y w^{67 c 23}$ and $m o f$ embryos with alpha-tubulin antibody to visualize the organization of spindle fibres. Around 66\% of $m o f^{d}$ embryos as opposed to only $7 \%$ of $y w^{67 c 23}$ embryos exhibited attachment of spindle fibres all over the chromsomes instead of the kinetochore, indicating disruption of the spindle fibre assembly and therefore leading to improper movement of chromosomes during anaphase resulting in lagging chromosomes. Number of embryos counted in the present study is 100 (Figure 7A, 7B).

The integrity of cell's cytoskeleton is crucial for the first occasion of vasa localization in the preplasmic cytoplasm as well as second occasion in the pole plasm.

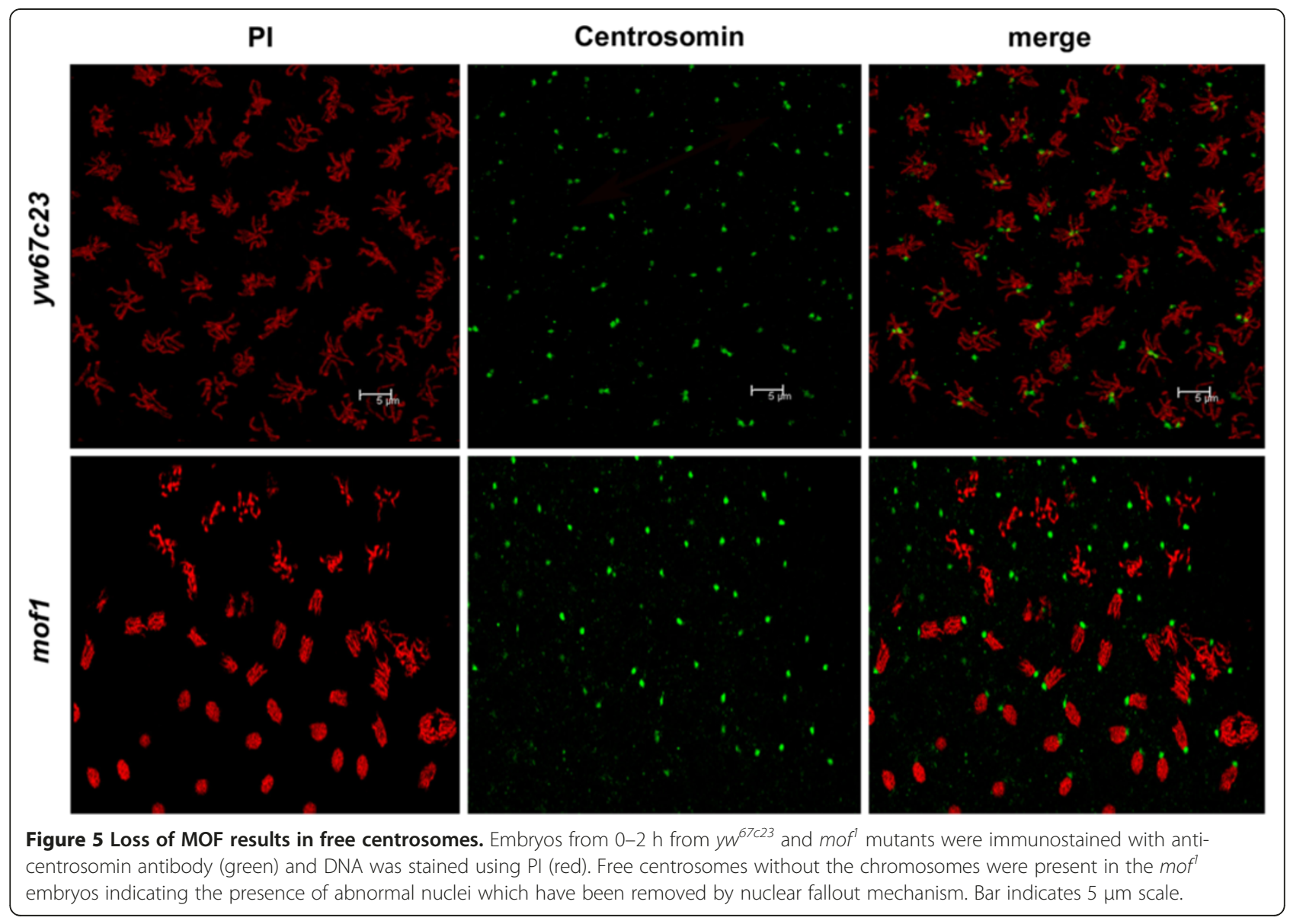



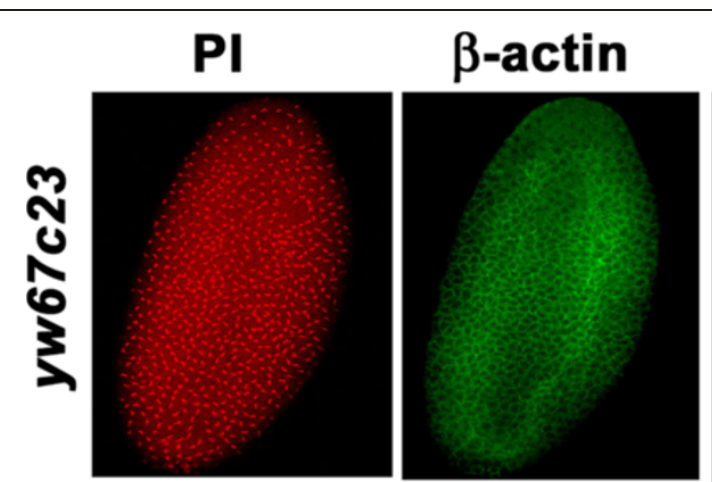

\section{merge}
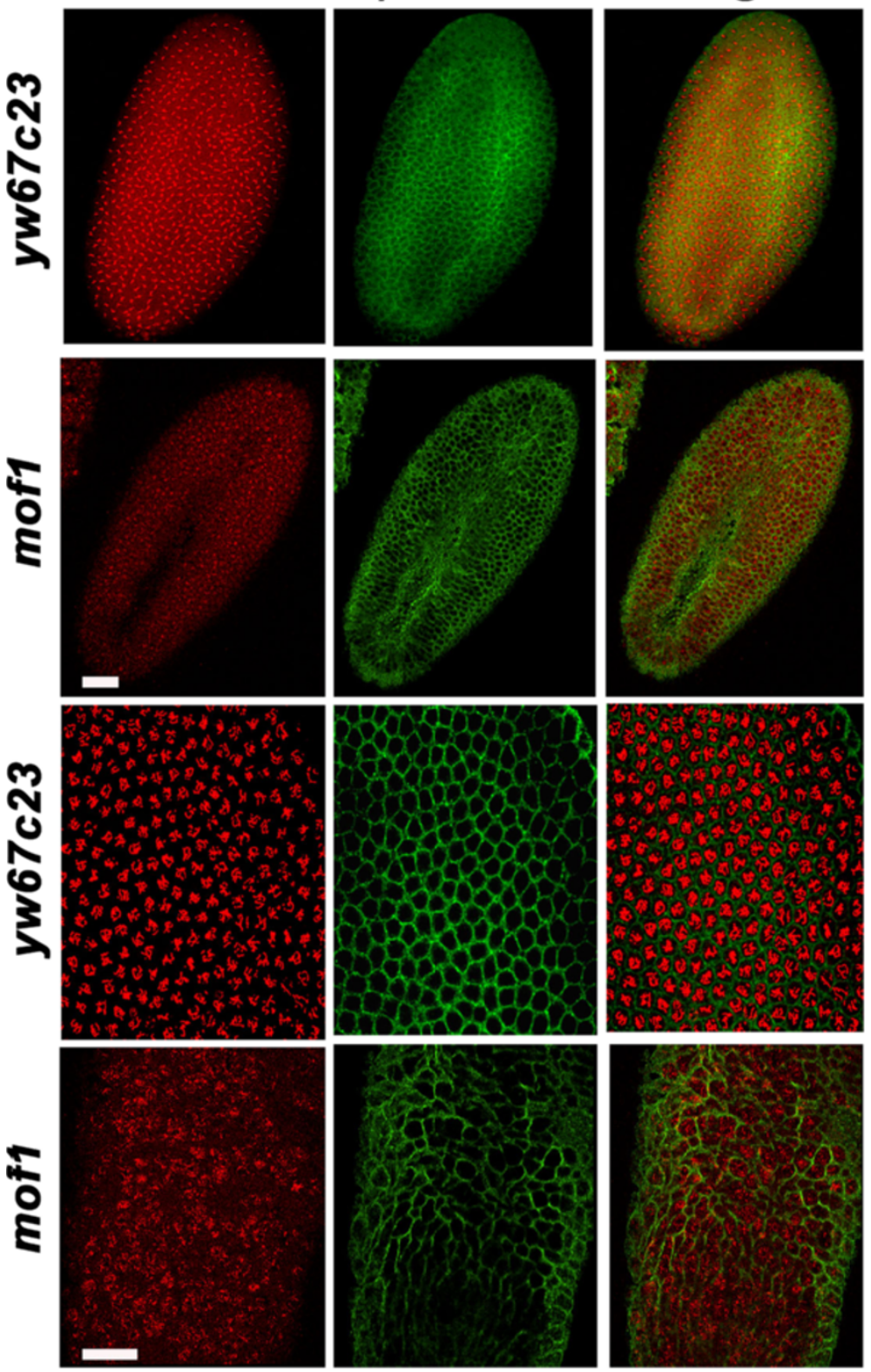

Figure 6 Defects in actin cytoskeleton in the mof $^{1}$ heterozygotes. Early embryos ( $0-2$ h) were stained with $\beta$-actin (green) antibody in both $y w^{67 c 23}$ and mof $^{\prime}$ embryos. Pl is used to stain the DNA. The honeycomb like structure which is characteristic of actin cytoskeleton is largely disrupted by the mof mutation. There are few cells which do not have chromsomes in them indicating abnormal nuclei which have been dropped into the cortex and digested by the yolk nuclei. Bar indicates $10 \mu \mathrm{m}$ scale.

Proper function of the cytoskeleton is important for nuclear migration leading to formation of pole cells. Here $y w^{67 c 23}$ and $m o f^{1}$ embryos were immunostained with antibody against vasa which selectively stains the pole cells. As anticipated we observed drastic reduction in the number of pole cells in the $m o f^{l}$ embryos compared to control $\left(y w^{67 C 23}\right)$ indicating that MOF is required for proper nuclear migration and formation of pole cells (Figure 7C, 7D).
Elevated levels of DNA damage in mof heterozygous embryos

We next wanted to study more specific role of MOF in DNA damage. Thus mof heterozygote embryos as well as control embryos were used in an assay that determines the extent of DNA damage (single, double stranded DNA breaks) [20]. Genomic DNA was isolated from the embryos $(0-2 \mathrm{~h})$ and incubated with T4 DNA kinase and 32P ATP. The amount of incorporation of 


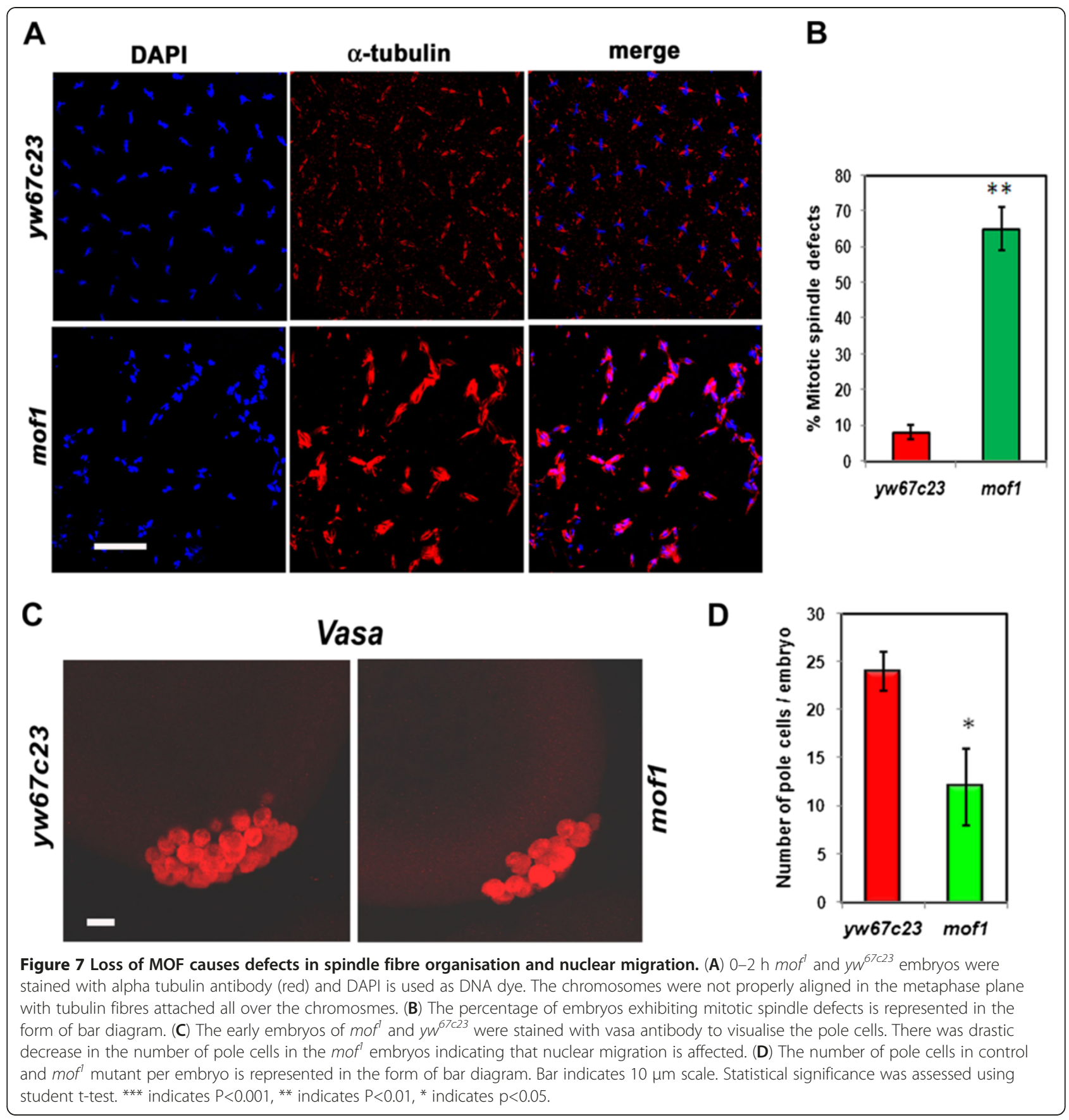

32PATP determined the number of exposed 5' phosphate groups in the DNA, indicating the number of single and double stranded lesions. Genomic DNA from $m o f^{1}$ embryos showed a highly elevated level of P32 incorporation of $6500 \pm 370 \mathrm{cpm} / \mathrm{ng}$ compared to the controls which is $1011 \pm 200 \mathrm{cpm} / \mathrm{ng}$ suggesting that the increase in lesions in mof embryos is due to progression through mitosis with damaged DNA or incompletely replicated DNA. To further confirm the double strand breaks observed in the mof ${ }^{1}$ heterozygote we carried out western blot studies using phospho H2Av antibody. As expected in $m o f^{l}$ heterozygotes we observed an increase in the levels of $\mathrm{H} 2 \mathrm{Av}$-phosphorylation when compared to control (Figure 8).

\section{Abnormal nuclei are eliminated by Chk2 activation}

Late syncytial embryos of Drosophila exhibit two-stage response to DNA damage or replication defects [21]. Two different kinase pathways, ATM/Chk2 pathway and ATR/Chk1 pathway play a major role in response to 


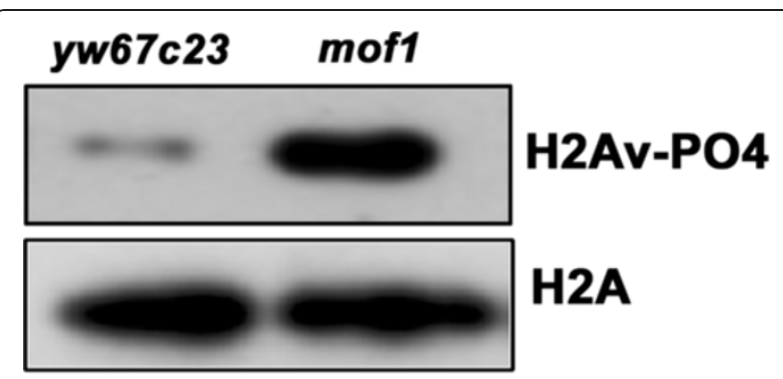

Figure 8 mof $^{1}$ mutation causes double strand breaks in DNA. Total protein was isolated from yw67c23 and mof1 heterozygous embryos and western blot was carried out using H2Av-PO4 antibody. Here H2A antibody was used as loading control. An increase in the level of phosphorylation of H2Av was observed in the mof1 heterozygotes.

DNA damage that is evolutionarily conserved. The DNA checkpoint mediated by mei-41 and grp, the Drosophila orthologs of ATR and Chk1 kinases, respectively, delay entry into mitosis via inhibitory phosphorylation of Cdk1, which allows repair of DNA damage or completion of DNA replication [22,23]. When this checkpoint fails, a second control operating during mitosis is activated, that results in changes in spindle structure and chromsome segregation to stop propagation of defective or damaged nuclei. This second step of control is mediated by activation of Chk2 by centrosomal inactivation [24]. The increased number of fall out nuclei and defects during early mitosis in the mof heterozygous embryos led us to speculate the possible involvement of a DNA replication dependent or DNA damage dependent cell cycle checkpoint defect. Drosophila embryos that lack Chk1 homologue ( $r r p)$ and ATR homologue (mei-41) show inactivation of centrosome during the late stages of syncytial division proving that both the homologues are not required for centrosome inactivation [21].

To show that DNA replication checkpoint is intact in the $m o f^{l}$ embryos, we studied the levels of grp (Chk1) and mei-41 (ATR) and we found that their levels remained the same in syncytial cycles 10-13 (Figure 9A). Also the levels of cyclins remained the same in the wild type and mof embryos in syncytial cycles 10-13 indicating that our data do not support a role of Drosophila mof in the control of cell cycle in the syncytial embryos through regulation of cyclins and grp. Thus our data do not support a role for Drosophila MOF in control of cell cycle timing in syncytial embryos via regulation of cyclins or grp levels.

The defective mitotic spindles that are short, anastral and associated with poorly aligned chromosomes in the mof embryos exhibited key features reminiscent of Chk2 mediated centrosomal inactivation. This led us to investigate the possible role of checkpoint gene Chk2 in this event. Total RNA was isolated from syncytial cycles 1013 of control $y w^{67 c 23}$, mof $f^{1}$ heterozygotes and RT-PCR was carried out using Chk2 specific primers. We observed increase in the transcript level of Chk2 by 4 -folds in the $m o f^{l}$ embryos compared to $y w^{67 c 23}$ control indicating Chk2 mediated centrosome inactivation (Figure 9B). To further confirm MOF mediated Chk2 regulation we have conducted the mof knock down experiment using dsRNA in S2 cells. The expression of Chk2 was found to be enhanced upon mof depletion. GFP dsRNA did not cause any significant change in levels of mof and thus used as control in the RNAi study (Figure 9B').

Since Chk2 is a major target of ataxia telangiectasiamutated (ATM), the expression pattern of ATM in mof $f^{t}$ heterozygous embryos was also studied. We observed that there was pronounced increase in levels of ATM in mof heterozygotes. As reported earlier [11] we also observed increased expression of $p 53$ in $m o f^{l}$ heterozygous embryos indicating that mof mutation causes spontaneous DNA damage leading to the activation of ATM-Chk2 pathway (Figure 9A).

\section{Centrosome inactivation in asynchronous nuclei of syncytial mof heterozygous embryos}

Drosophila Chk2 is encoded by mnk (maternal nuclear kinase) gene [25] and mnkp6 homozygous null mutation flies produce DNA damage induced apoptosis [26]. To further confirm ATM/Chk2 mediated centrosomal inactivation, we crossed $m o f^{l} / F M 7$ virgin females with mnkp6 males to produce heterozygous $m o f^{1} /+; m n k^{p 6} /+$ flies. The $m o f^{1} /+; m n k^{p 6} /+$ females were further mated with wild type males and $0-2 \mathrm{~h}$ embryos were collected. These embryos were stained with PI to check for nuclear fallout. The $m o f^{l}$ embryos exhibited high severity fall out nuclei (more than 5 fall out nuclei/embryo) while $m o f^{l} /+; m n k^{p 6} /+$ embryos had only low severity fall out nuclei (less than 5) (Figure 9C). Thus Chk2 activation contributes significantly to the mof $^{l}$ phenotype in syncytial embryos.

\section{Discussion}

MOF is a member of MYST family of histone acetyl transferases and is the essential component of the Xchromosome dosage compensation system in Drosophila. All MOF deficient mouse embryos fail to develop the expanded blastocyst stage and die at implantation in vivo. In the present study we observed loss of maternal MOF in the Drosophila embryos caused mitotic defects during early syncytial cycles and chromosomal aberrations as visualized by the presence of chromatid bridges and lagging chromosomes. These defects occur spontaneously in mof heterozygyotes without stress and resemble the defects induced by X-ray irradiation or chemical treatment of wild type embryos [27]. Our data has shown that endogenous DNA damage occurs during the process of development as shown by the presence of single and double 


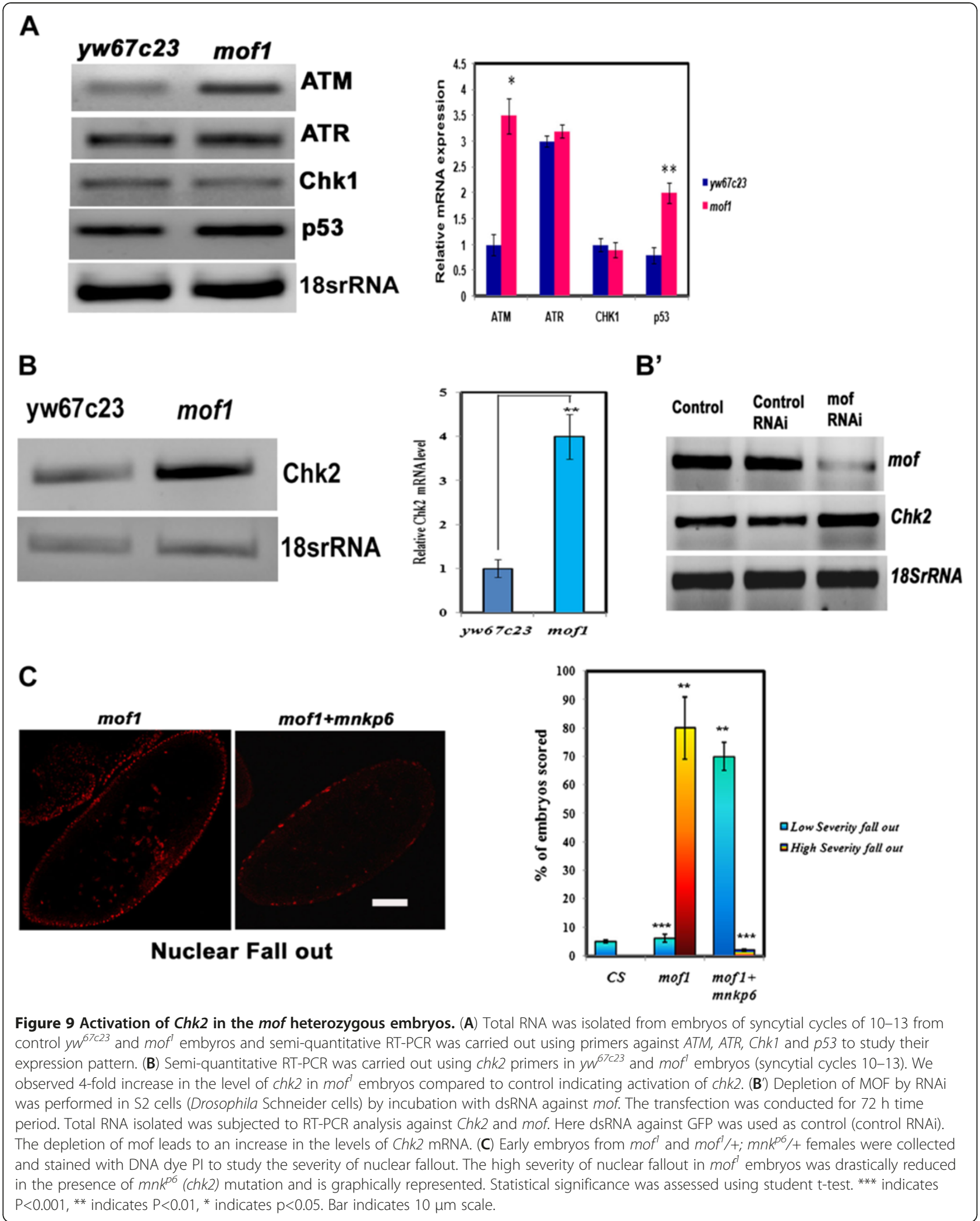


stranded DNA breaks. Similar phenotypes like spontaneous mitotic defects and chromosomal aberrations in Drosophila were also observed in reca5 DNA helicase mutants that are involved in DNA replication and maintainance of genomic integrity [28]. MOF is an essential component of dosage compensation complex and homozygotes for the mutation do not survive beyond late larval stages. The nuclei in mof early embryos are large and fragmented resembling mitotic catastrophe. The typical mitotic wave in wild type embryos is disrupted due to the presence of abnormal nuclei in the mof heterozygotes. Such abnormal nuclei are PH3 negative and appear in clusters [29]. Cellularisation occurs during the interphase of $14^{\text {th }}$ nuclear division. During this stage the actin filaments in $m o f^{d}$ embryos loose the typical honeycomb like structures often leading to empty cages without the chromosomes. The empty cages are indicative of the presence of abnormal nuclei that are $\mathrm{PH} 3$ negative and have been eliminated by nuclear fallout while the centrosomes are still retained in the cortex. A small percentage of embryos also show telophase defects like rounding off of the nuclei while the chromosomes are still in the anaphase stage. Similar mitotic defects were also observed in the case of another $m o f$ allele $\left(m^{3} f^{3}\right)$. The late larval lethality of $m o f$ homozygotes were rescued to $100 \%$ with the addition of mof transgene in the mutant genetic background while the mitotic defects in the mof heterozygote embryos were partially rescued.

In general every organism tries to protect itself by preventing these abnormal nuclei from being incorporated into forming adult structures [30]. Mutation of PcG genes which are components of chromatin remodeling that aid in the maintenance of transcriptional state during embryogenesis also resulted in the formation of abnormal nuclei [19]. Also the severity of the fall out nuclei in the $m o f^{d}$ heterozygotes was high containing more than 5 fall out nuclei per embryo which was reverted back to normal in the presence of wild type mof transgene. The response to DNA damage and mitotic defects maintain genomic stability by blocking chromosome segregation and removing the abnormal nuclei by nuclear fallout mechanism. Staining with PH3 antibody and DNA dye in the syncytial embryos is a good system to detect irregular or damaged DNA in Drosophila and also for studying maternal genes required for mitosis and genomic stability. The abnormal nuclei that stain negatively for $\mathrm{PH} 3$ are asynchronous and are seen during nuclear cycles 11-13. Following mitotic failure the defective nuclei drop into the interior of embryos and free centrosomes are seen in the cortex [29]. In the wild type embryos all the nuclei are in actively dividing phase compared to mof heterozygote where in nondividing nuclei are also present.

In a variety of systems, cell cycle checkpoint defects lead to progression into mitosis with damaged DNA or incompletely replicated DNA leading to "mitotic catastrophe", a process that is distinct from apoptosis [31]. In syncytial Drosophila embryos damaged or incompletely replicated DNA triggers centrosome inactivation during mitosis leading to defects in spindle fibre assembly and chromosome segregation [24]. The hallmark of DNA damage response (DDR) involves the phosphorylation of histone variant $\mathrm{H} 2 \mathrm{AX}$ that play an essential role in the recruitment and retention of downstream proteins involved in DNA repair. In addition to this $\gamma-\mathrm{H} 2 \mathrm{AX}$ is also involved in the transduction and amplification of DDR from megabase domains surrounding the damage site [32]. In our studies using $m o f^{l}$ heterozygotes we observed increase in single and double stranded DNA breaks and as well as $\mathrm{H} 2 \mathrm{Av}$ phosphorylation revealing the occurrence of DNA damage event.

Drosophila Chk2 plays a vital role in response to stress. DNA damage leads to increased localization of Chk2 to centrosomes and spindle fibres and also Chk2 is the signal for mitotic catastrophe that disrupts centrosome function leading to elimination of the abnormal nuclei [24]. It was also reported that mutation of $M n k$ gene (Drosophila homolog of Chk2) prevents centrosome inactivation and suppresses defects associated with chromosome segregation in response to damaged or incompletely replicated DNA. In our study we observed increased level of Chk2 in the mof heterozygotes in response to the damaged nuclei causing centrosome inactivation resulting in elimination of the damaged nuclei. The number of abnormal or damaged nuclei was reduced in the embryos of $m o f^{l} /+; m n k^{p 6} /+$ mothers indicating that mutation of $m n k^{p 6}$ prevents inactivation of centrosomes and hence loss of nuclei from the cortex. Unlike the cell cycle delays that occur to repair the damaged DNA or incompletely replicated DNA, Drosophila embryonic system utilizes the delay to identify and discard those abnormal nuclei. When the DNA lesions enter into mitosis, Chk2 is activated as a response and leads to centrosomal inactivation and delinks the chromosomes from their centrosomes which ultimately results in loss of the nuclei [29]. It has been proposed that Chk2 functions at two points during early embryogenesis in response to genotoxic stress. At the onset of mitosis DNA lesions leads to activation of Chk2 that target proteins involved in centrosomal spindle activity and in maintaining $\gamma$ TURC localisation. This causes failure in anaphase chromosome segregation. Once failure of mitotic division occurs, Chk2 causes centrosomal inactivation and disrupts the link between centrosomes and nuclei. Since centrosomes anchor nuclei to the cortex, Chk2 response to DNA damage results in loss of nuclei from the cortex [33]. The sensing of DNA lesions by DDR machinery occurs in a complex and heterogeneous chromatin environment $[34,35]$. 
Earlier reports also emphasized on the alteration in the chromatin structure that helps in the sensing and as well as spreading of the DNA damage response apart from double strand breaks [36-38].

DNA damage induces the activation of chromatin bound Chk2 by a chromatin derived signal resulting in the dissociation of the activated Chk2 from the chromatin. Chk2 is phosphorylated at T68 by ataxia telangiectasiamutated (ATM) and transmits the DNA damage signals from the upstream phosphatidylinositol 3'-kinase like kinases to the effector substrates including p53, Braca1, Cdc25A and Cdc25C [39]. In addition Chk2 has been reported to phosphorylate p53, thereby enhancing the transcriptional activity of p53 responsive genes [40]. Further the functional link between p53 and Chk2 during DNA damage occurs through the phosphorylation and acceleration of degradation of $\mathrm{Hdmx}$, a negative regulator of p53 [41].

This study revealed for the first time the role of MOF during early embryogenesis in Drosophila apart from dosage compensation and response to ionizing radiation.

\section{Conclusions}

Recent investigations have clearly demonstrated the role of MOF in response to ionizing radiation is conserved in Drosophila melanogaster. In human cells knockdown of hMOF results in loss of H4K16Ac and destabilization of nucleosomes that correlates with regions of chromatin decondensation. While acetylated H4 K16 appears to 'open up' the Drosophila male X chromosome to make it more accessible to transcription, which is an important part of the dosage compensation mechanism in the fly. Reduced levels of MOF in mammals correlate with decreased H4K16Ac, cell proliferation, cell survival and increased genomic instability. Drosophila haploinsufficency of maternal MOF causes several mitotic defects in the syncytial embryos and a large number of abnormal nuclei have been removed through the process of nuclear fallout. The increased number of abnormal or fall out nuclei correlated with reduced nuclear density in syncytial blastoderm embryos of mof heterozygotes. Our study demonstrates that in response to spontaneous DNA damage (increased number of single and double stranded DNA breaks) in mof heterozygotes, Chk2 is activated leading to centrosomal inactivation and loss of damaged nuclei from the cortex of the syncytial embryos. Furthermore removal of one copy of Chk2 in the mof mutant background considerably reduced the number of fall out nuclei in the syncytial embryos indicating the restoration of genomic stability. Hence MOF seems to play a crucial role in ensuring genomic stability during early embryogenesis both in mammals and Drosophila.

\section{Methods}

\section{Fly stocks}

Flies were cultured at standard corn meal agar food at $25^{\circ} \mathrm{C}$. $y w^{67 c 23}$ was obtained from flybase. $m o f^{7}, m o f^{3}, m o f^{3}+$ 18H1and $m n k^{p 6}$ fly stocks were kind gift from John C. Lucchesi, Joel C. Eissenberg and William E. Theurkauf respectively. Both $m o f^{d}$ and $m o f^{3}$ are null alleles of $m o f$ [11].

\section{Immunostaining of Drosophila embryos}

Drosophila embryos were dechorionised with $50 \%$ commercial bleach for 2-3 minutes and fixed with paraformaldehyde/heptane mix for 15-20 min. Primary antibodies for immunostaining were used in the following dilution: goat anti-vasa (1:20), rat anti- $\alpha$-tubulin (1:20), rabbit anti-PH3 (1:50), mouse anti- $\beta$-actin (1:30). Goat or donkey raised FITC, Cy3 and Cy5 conjugated secondary antibodies were used at a dilution of 1:50. Embryos were then mounted in Vectashield mounting media containing PI or DAPI and viewed using confocal microscope (FV1000, Olympus, Japan).

\section{Total RNA isolation and RT- PCR analysis}

Total cellular RNA from embryos was isolated by Trizol (Invitrogen). RNase-Free DNase treatment was subsequently carried out to remove DNA contaminants and further cleaned using RNeasy Mini Kit (Qiagen, Germany). Three micrograms of RNA was used for first strand cDNA synthesis using SuperScript ${ }^{\text {TM }}$ (Invitrogen, USA). PCR analysis was carried out using the following primers

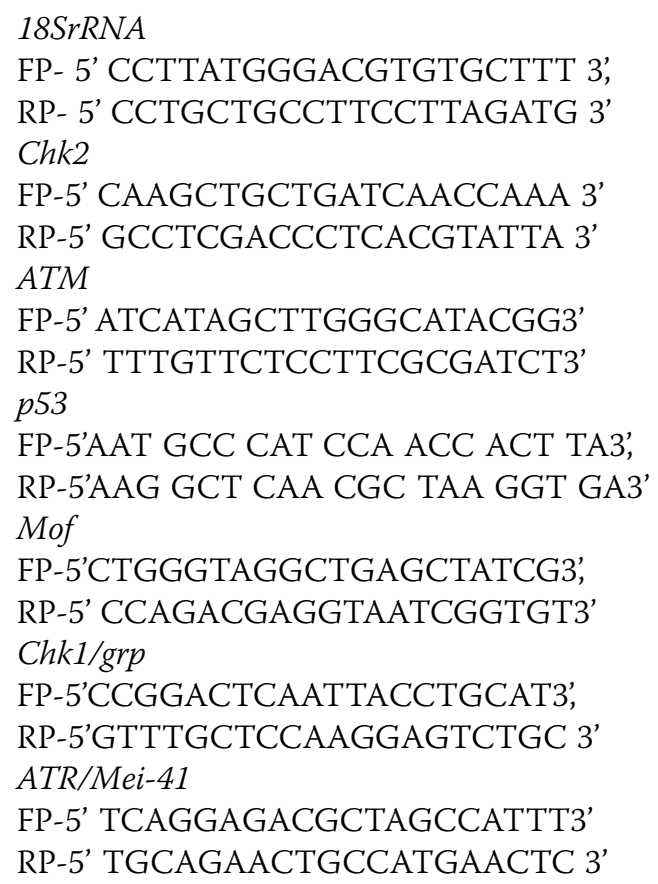

Total protein isolation and western blot analysis

Nearly $0.1 \mathrm{gm}$ of embryos were collected and thoroughly homogenized in lysis buffer (6\% SDS, 1 mM EDTA, 2 mM 
PMSF, $10 \mu \mathrm{g} / \mathrm{ml}$ Aprotinin, $10 \mu \mathrm{g} / \mathrm{ml}$ Leupeptin, $10 \mu \mathrm{g} / \mathrm{ml}$ Pepstatin). The lysed samples were boiled at $95^{\circ} \mathrm{C}$ for 5 minutes and centrifuged at $12,000 \mathrm{rpm}$ for 10 minutes at $4^{\circ} \mathrm{C}$. The supernatant was collected and western blot analysis was carried out by standard protocols using MOF (1:300), ß-actin (1:500) (Abcam) and H2Av-PO4 (1:500) antibodies (LS biosciences).

\section{DNA damage assay}

In order to assess DNA damage, genomic DNA was isolated from $0-2 \mathrm{~h}$ methanol-fixed wild type control and $m o f^{d}$ embryos as described earlier with slight modifications [21]. $\mathrm{NaOH}$ lysis is followed by incubation at $65^{\circ} \mathrm{C}$ for $40 \mathrm{~min}$. The embryos were gently homogenised and treated with proteinase $\mathrm{K}$ for $8 \mathrm{~h}$ at $55^{\circ} \mathrm{C}$, followed by RNAse A treatment and phenol-chloroform extraction. Each sample of DNA (100 ng) was incubated at $37^{\circ} \mathrm{C}$ for 20 min in $25 \mu \mathrm{l}$ of a reaction mixture containing $50 \mathrm{mM}$ imidazole $\mathrm{pH}$ 6.4, $12 \mathrm{mM} \mathrm{MgCl} 2,1 \mathrm{mM} \beta$-mercaptoethanol, $100 \mu \mathrm{M}$ ADP, 20 units T4 DNA Kinase (Gibco BRL) and $2.5 \mu \mathrm{l}$ of $3000 \mathrm{Ci} / \mathrm{mmol}$ [32P]ATP (Amersham). Column purification was carried out using G-50 spin columns to remove unincorporated labeled nucleotides. The level of p32 incorporated into the genomic DNA was measured by liquid scintillation counter. Over 300 embryos were used to generate the DNA for each experiment and the experiments were repeated thrice.

\section{Knock down studies}

MOF knockdown by RNAi was conducted in S2 cells using Schnieder's insect medium supplemented with $10 \%$ fetal bovine serum at $25^{\circ} \mathrm{C}$. Here for the effective knock down of mof, we transfected $50 \mu \mathrm{g}$ dsRNA in S2 cells and were incubated for $72 \mathrm{~h}$ as described earlier [11]. Control RNAi experiments using GFP was also employed.

\section{Statistical analysis}

Statistical analysis was performed using the graph pad software to evaluate the significant difference between the control and treated samples. The results obtained were expressed as mean \pm SD. All the experiments were conducted in triplicates. Statistical significance was assessed using student t-test. ${ }^{* * * *}$ indicates $\mathrm{P}<0.001$, ** indicates $\mathrm{P}<0.01$, * indicates $\mathrm{p}<0.05$.

\section{Additional file}

Additional file 1: Rescue of mitotic defects in mof embryos by mof transgene.

\section{Abbreviations}

Mof: Males absent on the First; HAT: Histone acetyl transferase; DCC: Dosage compensation complex; PI: Propidium lodide; DDR: DNA damage response; mnk: Maternal nuclear kinase; PH3: Anti-phospho-Histone H3 (Ser10).

\section{Competing interests}

The authors declare that they have no competing interests.

\section{Authors' contributions}

SNCVLP, AS, MJR and DRC carried out the experiments. SNCLVP and MJR designed the experiments. UB and MPB conceived the idea, designed the experiment and wrote the manuscript. All authors read and approved the final manuscript.

\section{Acknowledgements}

The authors thank John C. Lucchesi, Joel C. Eissenberg, William E. Theurkauf and Bloomington Stock Centre for the fly stocks. The authors also thank M. Kuroda for the MOF antibody and Jordon Raff for the centrosomin antibody. This work was supported by Wellcome Trust, UK to authors MBP [GAP 0158] and UB [GAP 0065].

\section{Author details}

${ }^{1}$ Centre for Chemical Biology, Indian Institute of Chemical Technology, Hyderabad 500607, India. ${ }^{2}$ Functional Genomics and Gene Silencing Group, Centre for Cellular and Molecular Biology, Hyderabad 500007, India.

Received: 16 August 2012 Accepted: 18 January 2013

Published: 24 January 2013

\section{References}

1. Zhou BB, Elledge SJ: The DNA damage response: putting checkpoints in perspective. Nature 2000, 408:433-443.

2. Jaklevic BR, SU TT: Relative contribution of DNA repair, cell cycle check points and cell death to survival after DNA damage in Drosophila larvae. Curr Biol 2004, 14:23-32.

3. Voss AK, Thomas T: MYST family histone acetyltransferases take center stage in stem cells and development. Bioessays 2009, 31:1050-1061.

4. Morales V, Straub T, Neumann MF, Mengus G, Akhtar A, Becker PB: Functional integration of the histone acetyltransferase MOF into the dosage compensation complex. EMBO J 2004, 23:2258-2268.

5. Yang XJ: The diverse superfamily of lysine acetyltransferases and their roles in leukemia and other diseases. Nucleic Acids Res 2004, 32:959-976.

6. Smith ER, Pannuti A, Gu W, Steurnagel A, Cook RG, Allis CD, Lucchesi JC: The Drosophila MSL complex acetylates histone H4 at lysine 16 , a chromatin modification linked to dosage compensation. Mol Cell Biol 2000, 20:312-318.

7. Smith ER, Cayrou C, Huang R, Lane WS, Cote J, Lucchesi JC: A human protein complex homologous to the Drosophila MSL complex is responsible for the majority of histone $\mathrm{H} 4$ acetylation at lysine 16. Mol Cell Biol 2005, 25:9175-9188.

8. Li X, Wu L, Corsa CA, Kunkel S, Dou Y: Two mammalian MOF complexes regulate transcription activation by distinct mechanisms. Mol Cell 2009, 36:290-301.

9. Hilfiker A, Hilfiker-Kleiner D, Pannuti A, Lucchesi JC: Mof, a putative acetyl transferase gene related to the Tip60 and MOZ human genes and to the SAS genes of yeast, is required for dosage compensation in Drosophila. EMBO J 1997, 16:2054-2060.

10. Taipale M, Rea S, Richter K, Vilar A, Lichter P, Imhof A, Akhtar A: hMOF histone acetyltransferase is required for histone $\mathrm{H} 4$ lysine 16 acetylation in mammalian cells. Mol Cell Biol 2005, 25:6798-6810.

11. Pal- Bhadra M, Horikoshi N, Pushpavalli Sreerangam NCVL, Sarkar A, Bag I, Krishnan A, Lucchesi JC, Kumar R, Yang Q, Pandita RJ, Singh M, Bhadra U, Eissenberg JC, Pandita TK: The role of MOF in the ionizing radiation response is conserved in Drosophila melanogaster. Chromosoma 2011, http://dx.doi.org/10.1007/s00412-011-0344-7.

12. Shogren-Knaak M, Ishii H, Sun JM, Pazin MJ, Davie JR, Peterson CL: Histone H4-K16 acetylation controls chromatin structure and protein interactions. Science 2006, 311:844-847

13. Corona DF, Clapier CR, Becker PB, Tamkun JW: Modulation of ISWI function by site-specific histoneacetylation. EMBO Rep 2002, 3:242-247.

14. Akhtar A, Becker PB: Activation of transcription through histone $\mathrm{H} 4$ acetylation by MOF, an acetyltransferase essential for dosage compensation in Drosophila. Mol Cell 2000, 5:367-375.

15. Gupta A, Guerin-Peyrou TG, Sharma GG, Park C, Agarwal M, Ganju RK, Pandita S, Choi K, Sukumar S, Pandita RK, Ludwig T, Pandita TK: The mammalian ortholog of Drosophila MOF that acetylates histone $\mathrm{H} 4$ 
lysine 16 is essential for embryogenesis and oncogenesis. Mol Cell Biol 2008, 28:397-409.

16. Fraga MF, Ballestar E, Villar-Garea A, Boix-Chornet M, Espada J, Schotta G, Bonaldi T, Haydon C, Ropero S, Petrie K, Iyer NG, Perez-Rosado A, Calvo E, Lopez JA, Cano A, Calasanz MJ, Colomer D, Piris MA, Ahn N, Imhof A, Caldas C, Jenuwein T, Esteller M: Loss of acetylation at Lys 16 and trimethylation at Lys 20 of histone $\mathrm{H} 4$ is a common hallmark of human cancer. Nat Genet 2005, 37:391-400.

17. Tram U, Riggs B, Sullivan W: Cleavage and gastrulation in Drosophila embryos. In Encyclopedia of Life Sciences. London: Macmillan Reference Ltd; 2002.

18. Foe VE, Odell GM Edgar BA, Bate M, Martinez Arias A: Mitosis and morphogenesis in the Drosophila embryo, Point and counterpoint. In The Development of Drosophila melanogaster vol 1. Cold Spring Harbor, New York: Cold Spring Harbor Laboratory Press; 1993:149-300.

19. Dor E, Beck SA, Brock HW: Polycomb group mutants exhibit mitotic defects in syncytial cell cycles of Drosophila embryos. Dev Biol 2006, 29:312-322

20. Fogarty P, Campbell SD, Abu-Shumays R, Phalle BS, Yu KR, Uy GL, Goldberg ML, Sullivan W: The Drosophila grapes gene is related to checkpoint gene chk1/ rad27 and is required for late syncytial division fidelity. Curr Biol 1997, 7:418-426.

21. Sibon OC, Kelkar A, Lemstra W, Theurkauf WE: DNA replication/DNAdamage-dependent centrosome inactivation in Drosophila embryos. Nat Cell Biol 2000, 2:90-95.

22. Sibon OC, Stevenson VA, Theurkauf WE: DNA-replication checkpoint control at the Drosophila midblastula transition. Nature 1997, 388:93-97.

23. Sibon OC, Laurencon A, Hawley R, Theurkauf WE: The Drosophila ATM homologue Mei-41 has an essential checkpoint function at the midblastula transition. Curr Biol 1999, 9:302-312.

24. Takada S, Kelkar A, Theurkauf WE: Drosophila checkpoint kinase 2 couples centrosome function and spindle assembly to genomic integrity. Cell 2003, 113:87-99

25. Oishi I, Sugiyama S, Otani H, Yamamura H, Nishida Y, Minami Y: A novel Drosophila nuclear protein serine/threonine kinase expressed in the germline during its establishment. Mech Dev 1998, 71:49-63.

26. Xu J, Xin S, Du W: Drosophila Chk2 is required for DNA damagemediated cell cycle arrest and apoptosis. FEBS Lett 2001, 508:394-398.

27. Callaini G, Dallai R, Riparbelli MG: Cytochalasin induces spindle fusion in the syncytial blastoderm of the early Drosophila embryo. Biol Cell 1992, 74:249-254

28. Nakayama M, Yamaguchi S, Sagisu Y, Sakurai H, Ito F, Kawasaki K: Loss of RecQ5 leads to spontaneous mitotic defects and chromosomal aberrations in Drosophila melanogaster. DNA Repair 2009, 8:232-241.

29. Sakurai H, Okado M, Fumiaki I, Kawasaki K: Anaphase DNA bridges induced by lack of RecQ5 in Drosophila syncytial embryos. FEBS Lett 2011, 585:1923-1928.

30. Sullivan W, Daily DR, Fogarty P, Yook KJ, Pimpinelli S: Delays in anaphase initiation occur in individual nuclei of the syncytial Drosophila embryo. Mol Biol Cell 1993, 4:885-896.

31. Roninson IB, Broude EV, Chang BD: If not apoptosis, then what? Treatment-induced senescence and mitotic catastrophe in tumor cells. Drug Resist Update 2001, 4:303-313.

32. Polo SE, Jackson SP: Dynamics of DNA damage response proteins at DNA breaks: a focus on protein modifications. Genes Dev 2011, 25:409-433.

33. Raff JW, Glover DM: Centrosomes, and not nuclei, initiate pole cell formation in Drosophila embryos. Cell 1989, 57:611-619.

34. Misteli T, Soutoglou E: The emerging role of nuclear architecture in DNA repair and genome maintenance. Nat Rev Mol Cell Biol 2009, 10:243-254

35. Shi L, Oberdoerffer P: Chromatin dynamics in DNA double-strand break repair. Biochim Biophys Acta 2012, 1819:811-819.

36. Bakkenist CJ, Kastan MB: DNA damage activates ATM through intermolecular autophosphorylation and dimer dissociation. Nature 2003, 421:499-506.

37. Bencokova Z, Kaufmann MR, Pires IM, Lecane PS, Giaccia AJ, Hammond EM: ATM activation and signaling under hypoxic conditions. Mol Cell Biol 2009, 29:526-537.

38. Hunt CR, Pandita RK, Laszlo A, Higashikubo R, Agarwal M, Kitamura T, Gupta A Rie N, Horikoshi N, Baskaran R, Lee JH, Lobrich M, Paull TT, Roti JL: Hyperthermia activates a subset of ataxia-telangiectasia mutated effectors independent of DNA strand breaks and heat shock protein 70 status. Cancer Res 2007, 67:3010-3017.

39. Li J, Stern DF: DNA damage regulates Chk2 association with chromatin. J Biol Chem 2005, 280:37948-37956.

40. Takai H, Naka K, Okada Y, Watanabe M, Harada N, Saito S, Anderson CW, Appella E, Nakanishi M, Suzuki H, Nagashima K, Sawa H, Ikeda K, Motoyama N: Chk2-deficient mice exhibit radioresistance and defective p53-mediated transcription. EMBO J 2002, 21:5195-5205.

41. Chen LD, Gilkes M, Pan Y, Lane WS, Chen J: ATM and Chk2-dependent phosphorylation of MDMX contribute to p53 activation after DNA damage. EMBO J 2005, 24:3411-3422.

doi:10.1186/1471-2199-14-1

Cite this article as: Pushpavalli et al:: Drosophila MOF controls

Checkpoint protein2 and regulates genomic stability during early embryogenesis. BMC Molecular Biology 2013 14:1.

\section{Submit your next manuscript to BioMed Central and take full advantage of:}

- Convenient online submission

- Thorough peer review

- No space constraints or color figure charges

- Immediate publication on acceptance

- Inclusion in PubMed, CAS, Scopus and Google Scholar

- Research which is freely available for redistribution 